\title{
Strength and Absorption Rate of Compressed Stabilized Earth Bricks (CSEBs) Due to Different Mixture Ratios and Degree of Compaction
}

\author{
Abd Halid Abdullah ${ }^{1, *}$, Sasitharan Nagapan ${ }^{1}$, Anna Antonyova ${ }^{2}$, Kannan Rasiah ${ }^{3}$, \\ Riduan Yunus ${ }^{1}$, and Samiullah Sohu ${ }^{1}$ \\ ${ }^{1}$ Faculty of Civil and Environmental Engineering, UniversitiTun Hussein Onn Malaysia, 86400 \\ ParitRaja, BatuPahat, Johor, Malaysia \\ ${ }^{2}$ Faculty of Management, University of Prešov in Prešov, Prešov 08001, Slovak Republic \\ ${ }^{3}$ Department of Mechanical Engineering, Politeknik Port Dickson, Negeri Sembilan, Malaysia
}

\begin{abstract}
Compressed Stabilized Earth Brick (CSEB) is produced by compressing a mixture of water with three main materials such as Ordinary Portland Cement (OPC), soil, and sand. It becomes popularfor its good strength, better insulation properties, and a sustainable product due to its easy production with low carbon emission and less skilled labour required. Different types of local soils usedwill produce CSEB of different physical properties in terms of its strength, durability, and water absorption rate. This study focuses on laterite soil taken from the surrounding local area in Parit Raja, Johor, and CSEB samples are produced based on prototype brick size $100 \times 50 \times 30 \mathrm{~mm}$. The investigations are based on four different degree of compactions (i.e. 1500, 2000, 2500, and 3000 Psi) and three different mix proportion ratios of cement:sand:laterite soil (i.e. 1:1:9, 1:2:8, 1:3:7). A total of 144 CSEB samples have been tested at 7 and 28 days curing periods to determine the compressive strength (BS 3921:1985) and water absorption rate (MS 76:1972). It was found that maximum compressive strength of CSEB was $14.68 \mathrm{~N} / \mathrm{mm}^{2}$ for mixture ratio of $1: 3: 7$ at 2500 Psi compaction. Whereas, the minimum strengthis $6.87 \mathrm{~N} / \mathrm{mm}^{2}$ for 1:1:9mixture ratio at 1500 Psi. Meanwhile, the lowest water absorption was $12.35 \%$ for mixture ratio of $1: 2: 8$ at 3000 Psi; while the $1: 1: 9$ mixture ratio at 1500 Psi gave the highest rate of $16.81 \%$. This study affirms that the sand content in the mixture and the degree of compaction would affect the value of compressive strength and water absorption of CSEB.
\end{abstract}

\section{Introduction}

Brick is commonly used as building material for wall due to its ability to support live and dead loads, and also serve as heat insulation. It can be categorized as clay bricks, mortar brick, fired or unfired brick, etc. [1]. The prime advantage of utilizing Compressed Stabilized Earth Brick (CSEB) is that it utilizes local materials and reduces transportation costs since the production is in-situ. Other advantages include faster production and easier

\footnotetext{
*Corresponding author: abdhalid@uthm.edu.my
} 
construction method that generally requires less skilled labour. According to T. Morton [1], a striking contrast between CSEB and conventional brick is lower energy consumed during the production process, and as such less carbon emission. CSEB produces $22 \mathrm{~kg} \mathrm{CO}^{2} /$ tonne as compared to that of concrete blocks $\left(143 \mathrm{~kg} \mathrm{CO}^{2} /\right.$ tonne), fired clay bricks $(200 \mathrm{~kg}$ $\mathrm{CO}^{2} /$ tonne) and aerated concrete blocks (280-375 $\mathrm{kg} \mathrm{CO}^{2} /$ tonne) respectively [1- 3]. CSEB product is also said to be environmentally friendly and sustainable as it utilizes almost unlimited resource in its natural state that involve no pollution and negligible energy consumption, thus further benefiting the environment by saving biomass fuel [4 - 6].

The main process of producing CSEB involves soil preparation, compaction of mixture, and curing [7]. However, the detail production process involves eight stages including sieving the soil, measuring, mixing, checking the moisture content, moulding, quality control, humid curing and stacking, and curing and stacking [8]. CSEB requires careful and correct selection of the soil to get the best result. After pouring the mixture into the mould, a proper compaction pressure should then be applied. Curing of CSEB usually takes advantage from natural humid where bricks could be stacked immediately after compaction but the strength is gained over time. It is important to prevent rapid drying out; hence, the brick is moist cured under polythene sheet (or wet gunny) in the open air (relative humidity more than $70 \%$ is the best condition in ensuring maximum hydration of the used stabilizer) for about 28 days if cement is used as a stabilizer [9, 10].

CSEB made from different types of local soils will give different physical and thermal properties [11, 12]. In this study, CSEB is made from local laterite soil mixed with Ordinary Portland Cement (OPC) as a stabilizer, sand, and water. The primary objective of the study is to determine the optimum compressive strength and water absorption rate of CSEB due to different mixture ratios (i.e. cement:laterite:sand) and degree of compactions.

\section{Soil preparation for CSEB}

Initially, soil physical testing should be performed to ensure the suitability of laterite soil for CSEB production. The two types of test commonly carried out are Grain Size Analysis Test and Atterberg Limits Test.Grain Size Analysis Test refers to discerning the percentages of particles (by dry mass) within a specified particle size range across all the sizes represented for the sample. The distribution of particle sizes is used to distinguish the maximum particle size and the major portion of the particle sizes, as well as to characterize the soil, such as by the Unified Soil Classification System (USCS) [13]. This test uses a mechanical shaker equipped with various sieve sizes of $5 \mathrm{~mm}, 2 \mathrm{~mm}, 1.18 \mathrm{~mm}, 0.6 \mathrm{~mm}$, $0.425 \mathrm{~mm}, 0.3 \mathrm{~mm}, 0.212 \mathrm{~mm}, 0.15 \mathrm{~mm}, 0.063 \mathrm{~mm}$, and a pan at the bottom.

Atterberg Limits is the soil classification test to determine the soil's Liquid Limit (LL) and Plastic Limit (PL). The LL and PL are water contents at which the mechanical properties of soil changes. They are applicable to fine-grained soils, and are performed on soils fractions that pass the $0.425 \mathrm{~mm}$ (No. 40) sieve. The difference between PL and LL is defined as the Plasticity Index (PI). The LL defines water content at the boundary between liquid and plastic states. It is expressed as a percentage and determining the LL by the multipoint method using the Cone Penetration apparatus. The PL marks the boundary between semi-solid and plastic mechanical behaviour. However, in reality the material slowly transitions between the two. The PL is defined as the water content at which a $3 \mathrm{~mm}$ diameter rod of soil begins to crumble. The PI is the difference in water content between LL and PL. 


\section{CSEB production and sample preparations}

A total of 140 CSEB samples size $100 \times 50 \times 30 \mathrm{~mm}$ (as shown in Fig. 1) were produced with different mixture ratios and compaction pressures. The process started with preparing all the raw materials such as laterite soil, sand, OPC and water. The particle sizes must be 2 $\mathrm{mm}$ for sand and less than $5 \mathrm{~mm}$ for laterite soil in order to ensure the binding between all materials when mixed together. The three different mix proportion ratios of cement:sand:laterite soil employed in this study were 1:1:9, 1:2:8, 1:3:7. The added water should not be more than $15 \%$ by the ratio. The CSEB mixture was poured into a mould and then compacted using a hydraulic compaction machine.To maintain or avoid the water content in the CSEB samples from draining quickly during curing process, they were placed under covered area or protected from direct sunlight and rain, for two different time periods of 7 days and 28 days.

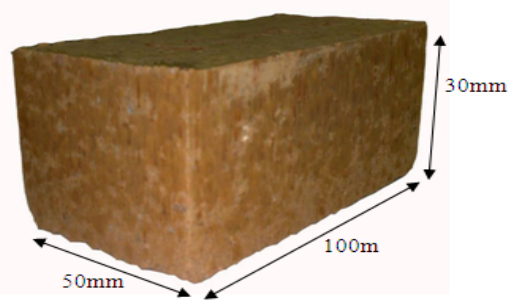

Fig. 1. The finished CSEB.

\subsection{Testing compressive strength of CSEB}

A total of 3 different samples of the mixture proportions and compaction pressures were taken into account. As a reference, the compressive strength value is referred to in BS 3921:1985 [13] which states that the minimum compressive strength of clay brick is 5 $\mathrm{N} / \mathrm{mm}^{2}$. To obtain accurate values of compressive strength of the surface layer of CSEB, metal plates lining were placed on both its top and bottom sides so that force from the compressive strength Universal Test Machine could be uniformly applied. The values of compressive strength were directly derived from the computer system which presented them in the form of graphs. Then, data were stored and later brought back for analysis.

\subsection{Water absorption rate}

The samples were tested at 7 and 28 days for the variable mentioned earlier and water absorption rate were taken after 3 days curing period. Based on MS 76:1972 [15], water absorption rate testwhich involved the cooling method where each sample was weighed and dried in an oven for 48 hours at a temperature of $105^{\circ} \mathrm{C}$. It was then soaked in water for 24 hours at room temperature. In order to get the percentage rate of water absorption, the weight of the sample after immersion was divided by the weight of dry sample and then multiplied by $100 \%$.

\subsection{Laboratory test results}

The results describing the characteristics of the laterite soil due to several laboratory tests are summarized and detailed in Table 1. 
Table 1. Identification and Characteristics of the Soil Used

\begin{tabular}{|c|l|c|}
\hline Test Types & \multicolumn{2}{|c|}{ Property } \\
\hline Atterberg Limits & Liquid Limit (LL) & 42.5 \\
\hline & Plastic Limit (PL) & 27.36 \\
\hline & Plasticity Index (PI) & 15.14 \\
\hline \multicolumn{3}{|l|}{} \\
\hline Chemical Characteristics & Carbon Dioxide, $\mathrm{CO}_{2}(\%)$ & 0.10 \\
\hline & Ferum Trioxide, $\mathrm{Fe}_{2} \mathrm{O}_{3}(\%)$ & 36.90 \\
\hline & Silicon Dioxide, $\mathrm{SiO}_{2}(\%)$ & 34.20 \\
\hline & Aluminum Oxide, $\mathrm{Al}_{2} \mathrm{O}_{3}(\%)$ & 25.40 \\
\hline & Titanium Dioxide, $\mathrm{TiO}_{2}(\%)$ & 0.64 \\
\hline & Potassium Oxide, $\mathrm{K}_{2} \mathrm{O}(\%)$ & 1.85 \\
\hline & Sulfur Trioxide, $\mathrm{SO}_{3}(\%)$ & 0.27 \\
\hline & Sodium Oxide, $\mathrm{Na}_{2} \mathrm{O}(\%)$ & 0.17 \\
\hline & Magnesium Oxide, $\mathrm{MgO}(\%)$ & 0.21 \\
\hline & \multicolumn{2}{|}{} \\
\hline \multicolumn{3}{|l|}{} \\
\hline Normalized Proctor Test & Optimum water content (\%) & 15 \\
\hline & Optimum cement content (\%) & 9 \\
\hline
\end{tabular}

\subsubsection{Compressive strength}

Based on the three mixture ratios, compressive strength tests were performed based on BS 3921:1985[14] to determine the maximum value of CSEBs. The tests were carried out using 3 samples, and the average value of the samples would be considered accordingly as the final value for compressive strength.It can be seen from Fig. 2 that the compressive strength of CSEB samples became higher as their age increased from 7 to 28 days.

\subsubsection{Correlation between compressive strength and sand content}

Fig. 3 generally shows that as the age of CSEB samples increased from 7 to 28 days regardless of the degree of compactions, the compressive strength would rise as the sand content was added more while reducing the laterite soil content.

For mixture ratio of 1:3:7, the laterite soil content was reduced around $9 \%$ and the sand content was added more with the same amount. Correlation between the different percentages of sand content and compaction pressures on the strength can be seen from Figures 3(a) and 3(b) for samples' age of 7 and 28 days. The maximum strength of $14.68 \%$ $\mathrm{N} / \mathrm{mm}^{2}$ was obtained for samples with mixture ratio of $1: 3: 7$ subjected to 2500 Psi compaction, while the minimum strength value of $6.87 \mathrm{~N} / \mathrm{mm}^{2}$ for mixture ratio of $1: 1: 9$ with compaction of 1500 Psi. Sand and gravel are also suitable to be used as additive in the soil as they will increase the quality of sand and also improve the particle size distribution, and therefore could affect the value of compressive strength of CSEB [16].

\subsubsection{Correlation between compressive strength and degree of compaction}

Fig. 4 shows that for all mixture ratios the increased in the degree of compaction pressures in producing CSEB samples would generally lead to the rise in compressive strength despite their ages. Furthermore, the optimum mixture ratio was found to be 1:3:7 as it gave the greatest strength regardless the age of samples. With that mixture ratio, the highest strength values were $12.88 \mathrm{~N} / \mathrm{mm}^{2}$ for 7 days old samples subjected to compaction of 3000 Psi, and $14.68 \mathrm{~N} / \mathrm{mm}^{2}$ for 28 days old samples subjected to compaction of 2500 Psi. In contrast, CSEB samples with mixture ratio of 1:1:9 subjected to 1500 Psi compaction gave 
the lowest strength values of $7.75 \mathrm{~N} / \mathrm{mm}^{2}$ and $6.87 \mathrm{~N} / \mathrm{mm}^{2}$ at the age of 7 and 28 days, respectively. It can be seen also from Figures 4(a) and 4(b) that the different sand content in the mixture ratios as well as degree of compaction applied could affect the compressive strength of CSEB samples. In general, by increasing the compactions from $5 \mathrm{MPa}$ to 20 $\mathrm{MPa}$, the strength can reach up to $70 \%$ [9]. Since currently there is no specific standard on the required strength of CSEB, the results of compressive strength values found from this study were compared and referred to the BS 3921:1985 [14]. Minimum strength specified in this standard for clay brick Damp-proof Course 1 is $5 \mathrm{~N} / \mathrm{mm}^{2}$. Thus, all values obtained are beyond the allowable strength specified in the standard.

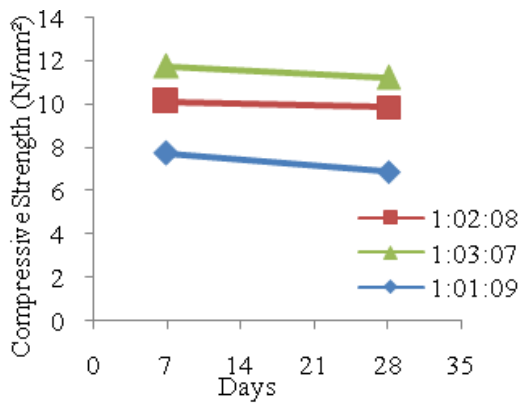

(a) Compaction of 1500 Psi

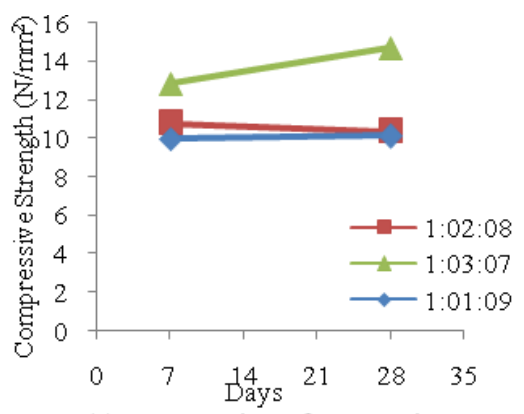

(c) Compaction of 2500 Psi

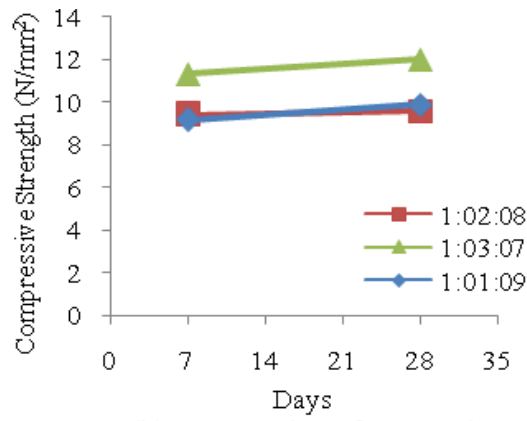

(b) Compaction of 2000 Psi

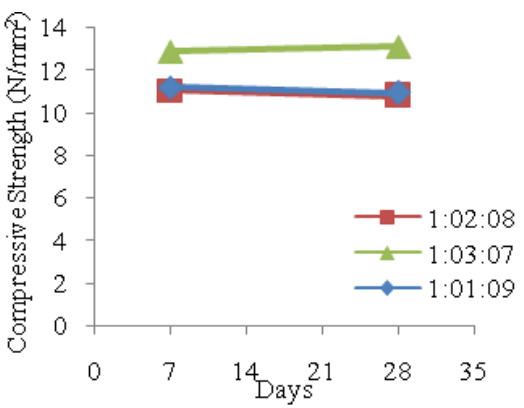

(d) Compaction of $3000 \mathrm{Psi}$

Fig. 2. CSEB strength due to mixture ratios \& Compaction vs. Samples' Age ( $7 \& 28$ days).

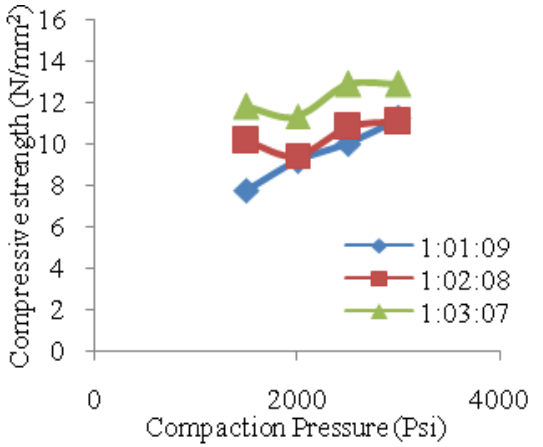

(a) Age of samples: 7 days

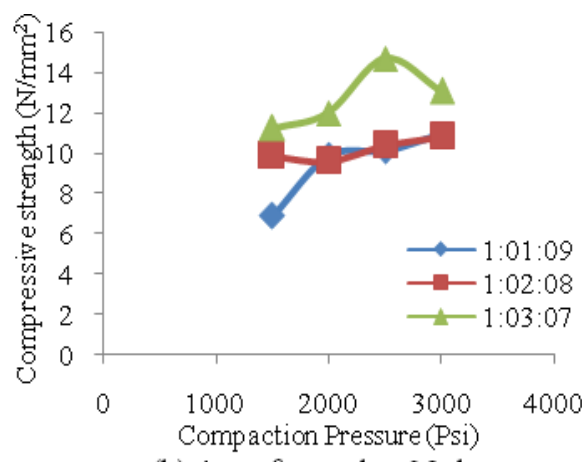

(b) Age of samples: 28 days

Fig. 3. Effect of sand content on the strength due to age of samples ( $7 \& 28$ days). 


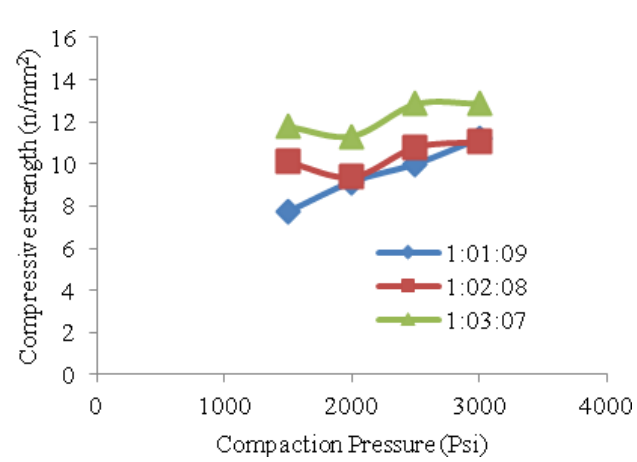

(a) Age of samples: 7 days

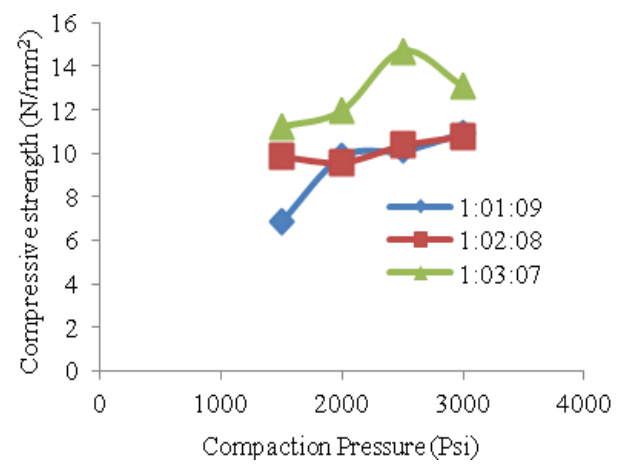

(b) Age of samples: 28 days

Fig. 4. Strength vs. compaction due to different age of samples ( $7 \& 28$ days).

\subsubsection{Water Absorption}

Water absorption rate for brick is of great concern as it will determine the material's workability due to the effect of weather. The results of rate of water absorption for CSEB samples in this study were compared with that of Load Bearing Bricks Class (1) as specified in the MS 76:1972 [15]. Although currently there is no specific standard of water absorption rate for CSEB, the actual practice in Malaysian construction industry has generally considered the rate of water absorption for bricks should be less than $15 \%$. Lower rate of water absorption indicates that the bricks are better in terms of its quality and resilience to weather effects, particularly when exposed to rain and sunlight.

Fig. 5(a) to Fig. 5(d) show results for water absorption of CSEB samples produced with different mixture ratios as well as subjected to different compaction pressures at the age of 7 and 28 days, respectively. It can be seen that the rate of water absorption rates for CSEB samples at 28 days old were lower as compared to that of 7 days old. This indicates that as the age of CSEB is increasing from 7 to 28 days, the hydration process of cement is getting more complete due to the curing process. Completion of the hydration process would result in the reaction between Calcium Oxide $(\mathrm{CaO})$ with water to produce Calcium Hydroxide $\mathrm{Ca}(\mathrm{OH})^{2}$ which will cover the empty spaces between particles in bricks and making CSEB impervious in nature. This condition could prevent the water absorption into the bricks. The lowest rate of water absorption was found to be $12.35 \%$ for 28 days old CSEB sample with mixture ratio of 1:3:7 subjected to 3000 Psi compaction. Whereas, the highest rate of water absorption was $16.28 \%$ for 28 days CSEB sample with mixture ratio of 1:1:9 subjected to compaction of 1500 Psi. Figure 5 also shows that the rates of water absorption were generally lower than $15 \%$ for CSEB samples produced with mixture ratio of 1:3:7 subjected to any degree of compactions (i.e. 1500, 2000, 2500, and 3000 Psi) regardless the samples' ages. Higher rate of water absorption of CSEB may cause swelling of stabilized clay fraction and resulting in losing strength with time. Water absorption and porosity of CSEB would increase with higher clay content, as well as decrease with cement content [2].

\subsubsection{Correlation between water absorption and compaction pressure}

The different degree of compactions applied in the production of CSEB the optimum water content in the stabilized mixtures. Fig. 6(a) and Fig. 6(b) exhibit that the rates of absorption generally decrease with the increase in compaction pressures. The optimum mixture ratio was found to be 1:3:7 as it generally gave the lower rate of absorption regardless the age of 
CSEB samples. Samples with that mixture ratio and compacted by 3000 Psi pressure, the lowest absorption rates were $14.05 \%$ and $12.97 \%$ for 7 and 28 days, respectively. In contrast, CSEB samples with mixture ratio of 1:1:9 subjected to compaction of 1500 Psi gave the highest absorption rates of $16.81 \%$ and $16.03 \%$ at 7 and 28 days, respectively.

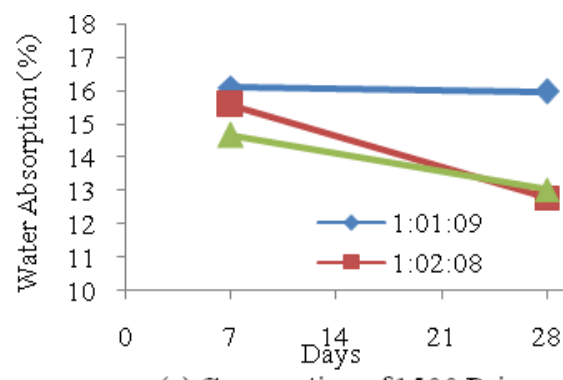

(a) Compaction of $1500 \mathrm{Psi}$

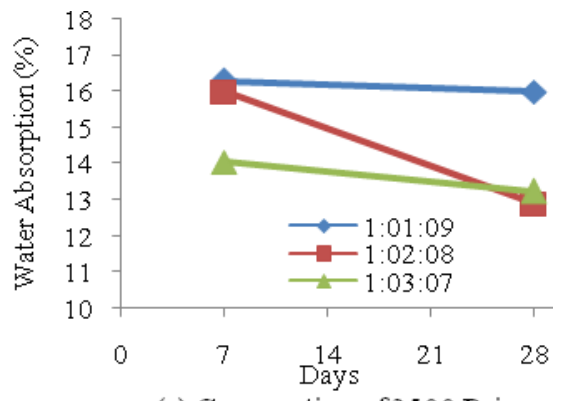

(c) Compaction of 2500 Psi

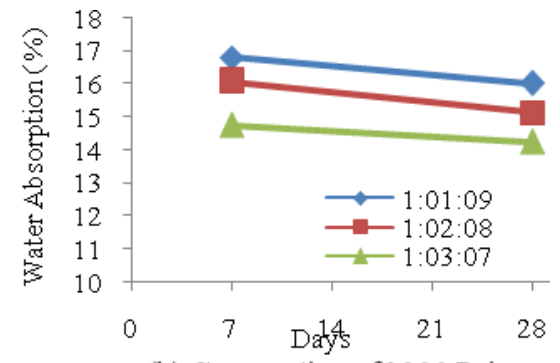

(b) Compaction of 2000 Psi

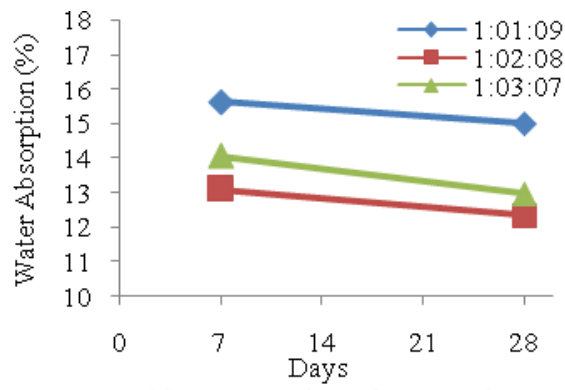

(d) Compaction of $3000 \mathrm{Psi}$

Fig. 5. Absorption due to mixture ratios / Compaction vs. Samples age ( $7 \& 28$ days).

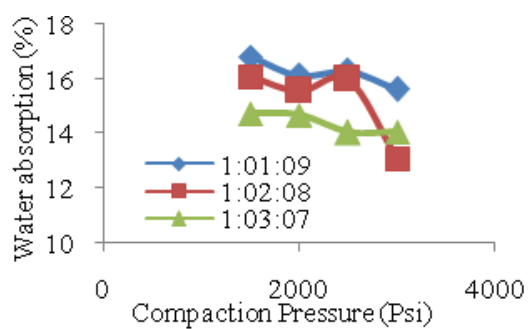

(a) Age of samples: 7 days

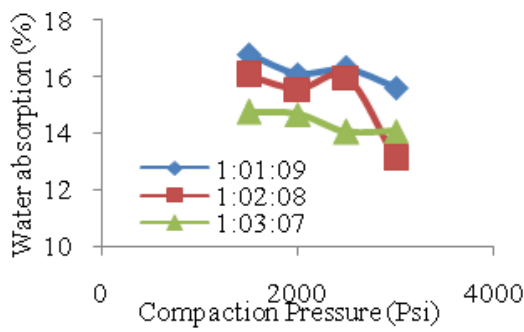

(b) Age of samples: 28 days

Fig. 6. Absorption vs. Compaction for different age of samples ( $7 \& 28$ days).

\section{Conclusions}

It can be firmly presumed that parameters such as particle size and moisture content of the soil can influence the strength of the CSEB. From the particle size of the soil, we can identify the composition of the soil. The composition of the soil can be adjusted until it falls within the ideal curve limit in particle size distribution to produce high strength CSEB. The mixture ratio plays a vital role in determining the soil-sand-cement strength. Properties of the soil can be the factor of producing the higher strength CSEBs. The quantity of gravel, sand, clay and silt of the soil must be suitable with the ratio of the mixture. Without perfect mixture ratio, the desired strength will not be achieved. Moreover, it can be affirmed that 
degree of compaction pressures applied in the production of CSEBs greatly affect the compressive strength and rate of water absorption.

We would like to express our appreciation to the staff at the Materials Engineering Laboratory, Universiti Tun Hussein Onn Malaysia (UTHM), for their assistance during the preparation and testing of samples. The authors are alsograteful to the UTHM for giving the financial support under the Short Term Grant (STG) No. U636.

\section{References}

[1] T. Morton, Earth masonry design and construction guidelines, Construction research communications limited, Berkshire, (2008)

[2] N. Ali, N.A. Zainal, M.K. Burhanudin, A.A.A. Samad, N. Mohamad, S. Shahidan and S.R. Abdullah, Physical and mechanical properties of compressed earth brick (CEB) containing sugarcane bagasse ash, MATEC Web Conf., 47, 1-7, (2016)

[3] J.C. Morel, A. Mesbah, M. Oggero and P. Walker, Building houses with local material: means to drastically reduce the environmental impact of construction, Building and Environment, 36, 1119-1126, (2001)

[4] S. Shahidan, H.B. Koh, A.S. Alansi and L.Y. Loon, Strength development and water permeability of engineered biomass aggregate pervious concrete, MATEC Web Conf., 47, 2-7, (2016)

[5] E.A. Adam and A.R.A. Agib, Compressed stabilized earth block manufacture in Sudan, UNESCO, France, (2001)

[6] E. Aminudin, M.F.M. Din, M.W. Hussin, A.H. Abdullah, K. Iwao and Y. Ichikawa, Properties of agro-industrial aerated concrete as potential thermal insulation for building, MATEC Web Conf., 47, 1-9, (2016)

[7] Gernot Minke, Building with earth: Design and technology of a sustainable architecture, Birkhauser Publishers, Switzerland, (2006).

[8] Auroville Earth Institute, UNESCO Chair Earthen Architecture, Retrieved on November 15, 2016 from http://www.earth-auroville.com/compressed_stabilised_earth_block_en.php

[9] A. Guettalaet, Durability of lime stabilized earth blocks. Courrier du Savoir, 02, 61-66, (2002)

[10]P.J. Walker, Strength and erosion characteristics of earth blocks and earth block masonry, Journal of Materials in Civil Engineering, 16(5), 497-506, (2004).

[11] S.K. Abu Bakar and A.H. Abdullah, Simulation of thermal performance in an office, Business Engineering \& Industrial Applications Colloquium, IEEE, 318-323, (2012)

[12] A.H. Abdullah, S.K.A. Bakar and I.A. Rahman, Indoor thermal performance of an office building using conventional brick versus interlocking compressed earth brick (ICEB) wall, International Journal of Construction Technology and Management, 1(1), 22-27, (2013).

[13]John T. Germaine and Amy V. Germaine, Geotechnical Laboratory Measurements for Engineers, John Wiley and Sons Inc., United States of America, (2009)

[14]BS 3921:1985. Specifications for clay brick, British Standards Institution, London, United Kingdom, (1985)

[15]MS 76:1972. Specification for bricks and blocks of fired brick earth, clay or shale, Part 2: metric units, Malaysia Standard, 22,(1972)

[16] German Appropriate Tech. Exchange and CRAterre, The basics of compressed earth block, Eschborn: Deutsches Zentrum fürEntwicklungstechnologien-GATE, (1991) 